\title{
Afterload reduction: a comparison of captopril and nifedipine in dilated cardiomyopathy
}

\author{
PIER G AGOSTONI, NICOLETTA DE CESARE, ELISABETTA DORIA, \\ ALVISE POLESE, GLORIA TAMBORINI, MAURIZIO D GUAZZI
}

From Istituto di Cardiologia, Centro di Studio Ricerche Cardiovascolari del Consiglio Nazionale delle Ricerche, University of Milan, and Fondazione "I. Monzino" and Istituto Ricerche Cardiovascolari "G. Sisini", Milan, Italy

SUMMARY Nifedipine and captopril are potent vasodilators and may be expected to help left ventricular failure by reducing afterload. Nifedipine $(20 \mathrm{mg}$ three times a day) and captopril ( $50 \mathrm{mg}$ three times a day) were added to an optimal regimen of digitalis and diuretics in a double blind crossover trial in 18 cases of dilated cardiomyopathy. New York Heart Association functional class rating symptoms and exercise tolerance times improved on captopril but not on nifedipine. The reduction in pulmonary capillary wedge pressure and the increase of cardiac output on captopril indicated that the augmented functional capacity may have resulted in part from an improved performance of the left ventricle. Although there were comparable decreases in systemic vascular resistance and presumably in impedence to ejection by the left ventricle on both drugs, the dimensions of the ventricular cavity were found to be reduced by captopril and augmented by nifedipine, and only captopril reduced the afterload (wall stress). In addition, the force-length relation (between left ventricular end systolic stress and end systolic diameter) was shifted to the left of baseline by captopril and to the right by nifedipine, suggesting that muscle contractility was reduced by nifedipine and not by captopril.

These results suggest that nifedipine and captopril have different effects on afterload and contractility and these may account for the different effects of these drugs on the performance of the heart and clinical responses.

Most vasodilators may be beneficial in both hypertension and cardiac decompensation. The angiotensin converting enzyme inhibitor, captopril, is such an example. ${ }^{1-3}$ The antihypertensive properties of the calcium channel blocking agents are well established, ${ }^{4}$ and nifedipine has been used to reduce ventricular afterload. ${ }^{5-8}$

Treatment of cardiac insufficiency in the advanced stage of dilated cardiomyopathy is still one of the most challenging tasks in clinical cardiology, and the poor prognosis justifies a search for more efficient methods of treatment. Although the combination of captopril with conventional treatment has been of benefit in many series of patients with refractory chronic congestive heart failure, ${ }^{9-12}$ these series did

Requests for reprints to Professor Maurizio D Guazzi, Istituto di Cardiologia, Via Bonfadini 214, 20138 Milan, Italy.

Accepted for publication 3 December 1985 not include many cases of dilated cardiomyopathy and the specific response of such patients may have been obscured. Acute pulmonary oedema due to dilated cardiomyopathy can be relieved by nifedipine ${ }^{56}$ but long term studies are lacking.

For these reasons we have studied the effects of these two agents in dilated cardiomyopathy. We performed a detailed haemodynamic study of the different effects of captopril and nifedipine on blood vessels (in terms of arterial and venous muscle relaxation) and on the myocardium (in terms of changes in heart rate and contractility) in a crossover trial.

\section{Patients and methods}

\section{PATIENTS}

Twenty six patients with chronic congestive heart failure caused by dilated cardiomyopathy of unknown cause were considered to be eligible, but 
Table 1 Clinical data on 18 patients with dilated cardiomyopathy

\begin{tabular}{|c|c|c|c|c|c|}
\hline Case & Age (yr) & Sex & $B S A\left(m^{2}\right)$ & $E C G$ & Previous drug treatment \\
\hline $\begin{array}{l}1 \\
2 \\
3 \\
4 \\
5 \\
6\end{array}$ & $\begin{array}{l}57 \\
54 \\
46 \\
61 \\
45 \\
58\end{array}$ & $\begin{array}{l}\mathbf{F} \\
\mathbf{M} \\
\mathbf{M} \\
\mathbf{M} \\
\mathbf{M} \\
\mathbf{M}\end{array}$ & $\begin{array}{l}1 \cdot 26 \\
1.93 \\
1.84 \\
1.80 \\
1 \cdot 75 \\
2 \cdot 00\end{array}$ & $\begin{array}{l}\text { SR } \\
\text { AF }+ \text { LBBB } \\
\text { SR } \\
\text { AF } \\
\text { LBBB } \\
\text { SR+ } \\
\quad 1 \text { degree AVB }\end{array}$ & $\begin{array}{l}\text { Digitalis, frusemide, spironolactone } \\
\text { Digitalis, ethacrynic acid } \\
\text { Digitalis, nitrates, hydrochlorothiazide } \\
\text { Digitalis, frusemide } \\
\text { Digitalis, nitrates, frusemide } \\
\text { Digitalis, ethacrynic acid }\end{array}$ \\
\hline $\begin{array}{r}7 \\
8 \\
9 \\
10 \\
11 \\
12 \\
13 \\
14 \\
15 \\
16\end{array}$ & $\begin{array}{l}68 \\
58 \\
55 \\
49 \\
58 \\
34 \\
62 \\
38 \\
46 \\
57\end{array}$ & $\begin{array}{l}M \\
M \\
M \\
M \\
M \\
M \\
M \\
F \\
M \\
M\end{array}$ & $\begin{array}{l}1.57 \\
2.12 \\
1.83 \\
1.99 \\
1.82 \\
1.76 \\
1.88 \\
1.45 \\
1.85 \\
1.80\end{array}$ & $\begin{array}{l}\text { SR } \\
\text { SR } \\
\text { AF } \\
\text { AF }+ \text { LBBB } \\
\text { SR } \\
\text { SR } \\
\text { SR } \\
\text { SR } \\
\text { SR } \\
\text { SR + } \\
1 \text { degree AVB }\end{array}$ & $\begin{array}{l}\text { Digitalis, frusemide } \\
\text { Digitalis, frusemide } \\
\text { Digitalis, nitrates, frusemide } \\
\text { Digitalis, frusemide, spironolactone } \\
\text { Digitalis, nitrates, hydrochlorothiazide } \\
\text { Digitalis, hydrochlorothiazide } \\
\text { Digitalis, frusemide } \\
\text { Digitalis, frusemide } \\
\text { Digitalis, ethacrynic acid } \\
\text { Digitalis, frusemide, spironolactone }\end{array}$ \\
\hline $\begin{array}{l}17 \\
18\end{array}$ & $\begin{array}{l}52 \\
49\end{array}$ & $\begin{array}{l}\mathbf{F} \\
\mathbf{M}\end{array}$ & $\begin{array}{l}1 \cdot 59 \\
1 \cdot 82\end{array}$ & $\begin{array}{l}\text { LBBB } \\
\text { SR }\end{array}$ & $\begin{array}{l}\text { Digitalis, hydrochlorothiazide } \\
\text { Digitalis, frusemide, spironolactone }\end{array}$ \\
\hline
\end{tabular}

BSA, body surface area; ECG, electrocardiogram; SR, sinus rhythm; AF, atrial fibrillation; LBBB, left bundle branch block; AVB, atrioventricular block.

three were lost to follow up, one died, and four were withdrawn because at excessive hypotension on treatment. The remaining 18 patients (Table 1 ) completed the study. All of them had evident cardiac dysfunction causing dyspnoea at rest and were easily fatigued; six of them also had orthopnoea despite treatment with digitalis and diuretics. Vasodilators (nitrates) were used in four cases and treatment was stopped seven days before the beginning of the study. Eleven patients had had cardiac symptoms for $>$ two years and the other seven had had dyspnoea for at least 10 months. Eleven subjects were in functional class IV (New York Heart Association) and seven were in class III. We excluded those patients who had supine systolic blood pressure $<100 \mathrm{~mm} \mathrm{Hg}$, angina pectoris, a history of or electrocardiographic signs of myocardial infarction, and hepatic or renal impairment (serum bilirubin or glutamic oxalacetic transaminase or both more than twice the upper limit of normal, and serum creatinine concentration $\geqslant 2 \mathrm{mg} / \mathrm{dl}$ ). Patients were deemed to be eligible for the study if they were capable of exercising for at least three minutes and no more than 12 minutes on a treadmill following the protocol used by the Captopril Multicenter Research Group. ${ }^{11}$

The study protocol was approved by our ethical research committee, and each patient gave informed consent.

\section{STUDY DESIGN}

Patients were admitted to the hospital, and during the first seven days physical examination, 12 lead electrocardiogram, and blood and urine laboratory tests were performed; the dosages of digitalis and diuretics were also adjusted until we judged that an optimal regimen had been achieved. This regimen was kept constant during the trial. At the end of this period a standard $6 \mathrm{ft}$ posteroanterior chest $x$ ray was taken to measure the cardiothoracic ratio, and echocardiographic and blood pressure (with random zero sphygmomanometer) measurements were obtained with the patient supine. An exercise test was performed to determine maximum physical capacity. After this, patients were randomly allocated to a treatment group and right heart catheterisation was carried out. Baseline records were obtained $30 \mathrm{~min}$ after catheter positioning when patients felt comfortable and heart rate and blood pressure had stabilised. Then nifedipine $(20 \mathrm{mg})$ or captopril $(50 \mathrm{mg})$ was administered and the haemodynamic variables were recorded again every $30 \mathrm{~min}$ for the next $120 \mathrm{~min}$. Baseline values were compared with those detected when the fall in blood pressure after the drug was greatest.

Patients continued to take the test drug three times a day as outpatients. Each day patients noted their symptoms in a diary and classified dyspnoea on a scale of 0 to 4 ( 0 when none occurred, $1+$ with more than ordinary activity, $2+$ with ordinary physical activity, $3+$ dyspnoea at rest, and $4+$ orthopnoea). We used the patient's dyspnoea grades to give a serial clinical function classification (from class I to IV).

For two months physical examination, exercise tests, and echocardiographic examination were performed each week. After this, patients were readmitted to hospital and non-invasive and invasive evaluations were repeated $90-120 \mathrm{~min}$ after the final dose of the agent. Then patients were switched to the other drug, and continued on it as outpatients. We 
considered a washout period to be unnecessary in view of the long duration of treatment. The study continued as described earlier. No complications were noticed with repeated haemodynamic monitoring. The cardiothoracic ratio was measured on chest $x$ rays obtained at the end of both treatment periods.

Both nifedipine $(20 \mathrm{mg}$ ) and captopril $(50 \mathrm{mg})$ were given in identical capsules in a double blind randomised fashion in both the short term and long term studies. Capsules containing an inactive preparation were given during the seven day run in period.

\section{SAFETY}

For the first three days of each drug treatment patients remained in hospital and blood pressure and symptoms related to hypotension were monitored. Hypotension with faintness on standing was experienced by three subjects while on nifedipine (one on nifedipine as second drug) and two while on captopril (one on captopril as second drug). In one of these, however, symptomatic hypotension was transient and he was able to continue on captopril; the other four patients could not and they were withdrawn from the trial. No other patients had excessive hypotension or related symptoms during treatment.

\section{HAEMODYNAMIC ASSESSMENT}

Circulatory measurements were obtained in fasting patients who were supine and had not received premedication. For right atrial, pulmonary arterial, and pulmonary capillary wedge pressure measurements and cardiac output determinations, a number 7 triple lumen flow directed thermodilution catheter was inserted percutaneously under local anaesthesia into an antecubital vein and floated under fluoroscopic guidance to the pulmonary artery and, when necessary, to the wedge position. Intra-arterial blood pressure was measured through a Teflon catheter needle introducted into a brachial artery. We used these variables to calculate systemic (SVR) and pulmonary (PAR) arteriolar resistance by the following formulas: $\mathrm{SVR}=\mathrm{AP}-\operatorname{rap} \times 1332 / \mathrm{CO}$ and $\mathrm{PAR}=\mathrm{PAP}$ - WPP $\times 1332 / C O$, where CO is cardiac output (average of three thermodilution determinations), and AP, rap, PAP, and WPP are mean arterial, right atrial, pulmonary arterial and pulmonary capillary wedge pressure respectively. Mean pressures were obtained by electronic damping, and heart rate was derived from the electrocardiogram. All these variables were recorded on a Hewlett-Packard eight channel direct writing recorder (model 7868/A).

\section{ECHOCARDIOGRAPHIC EVALUATION}

Left ventricular end systolic circumferential wall stress was taken as a variable that reflects afterload and was evaluated non-invasively on echocardiograms recorded in triplicate. We used the angiographically validated equation of Grossman and coworkers, ${ }^{13}$ as modified by Reichek et al ${ }^{14}$ to calculate end systolic circumferential wall stress (es CWS):

$$
\text { es CWS }=\frac{0.334 \times \text { Ps } / \text { LVIDs }}{\text { PWTs }\left(1+\frac{\text { PWTs }}{\text { LVIDs }}\right)}
$$

where Ps, LVIDs, and PWTs are systolic cuff arterial pressure, left ventricular minor dimension $(\mathrm{cm})$, and posterior wall thickness $(\mathrm{cm})$ respectively at end systole. Pressure was measured after the patient had been recumbent for $15 \mathrm{~min}$. An independent observer used a random zero sphygmomanometer to take three consecutive measurements with $5 \mathrm{~min}$ between measurements. Ultrasound and blood pressure readings were averaged to improve their accuracy; variablity was within $2 \%$ for ventricular diameter and within 5\% for wall thickness and systolic blood pressure. Two patients with atrial fibrillation, two with left bundle branch block, and two with both were excluded from this analysis because accurate echocardiographic recordings are difficult to obtain in the presence of these disorders.

We used a Hewlett-Packard cross sectional unit (model $77020 \mathrm{~A}$ ) for echocardiography. The end systolic dimension of the endocardial surface was measured as the shortest distance between the septal and posterior walls during systole. End systolic posterior wall thickness was measured by the leading edge to leading edge method as the point of maximal anterior motion. We analysed the means of three to five consecutive cycles. The end systolic stress-left ventricular end systolic diamater relation was taken as an index of the end systolic force length relation.

\section{STATISTICAL EVALUATION}

All values after treatment were compared with the baseline values by two way analysis of variance. Differences in means were assessed by Student's $t$ test.

\section{Results}

Eighteen patients completed the study; all of them had had nifedipine and captopril for eight weeks each in a crossover study (Fig. 1).

Mean exercise tolerance times on captopril were significantly better than baseline values or values on nifedipine (Fig. 2). Nifedipine treatment values were never significantly different from baseline values.

The mean functional class was significantly better while patients were on captopril than at baseline and 
on nifedipine treatment (Table 2). Changes in clinical class paralleled the changes in exercise tolerance in all but two patients.

Baseline values for mean arterial pressure averaged $83 \mathrm{~mm} \mathrm{Hg}$, and the mean cardiac index for the group was reduced $\left(2.51 / \mathrm{min} / \mathrm{m}^{2}\right)$. Pulmonary capillary wedge pressure was $<20 \mathrm{~mm} \mathrm{Hg}$ in all except one of the patients, and the mean value $(12 \mathrm{~mm} \mathrm{Hg})$ was lower than expected given the severity of con- gestive heart failure. This was probably because patients were on diuretics and on a salt restricted hospital diet. Mean systemic and pulmonary arteriolar resistance was 1480 and 145 dyn s $\mathrm{cm}^{-5}$ respectively.

Peak response to oral nifedipine occurred about 1.5 hours after administration. At this time there was a $20 \%$ reduction in mean arterial pressure that was mediated through a $29 \%$ decrease in systemic vascu-

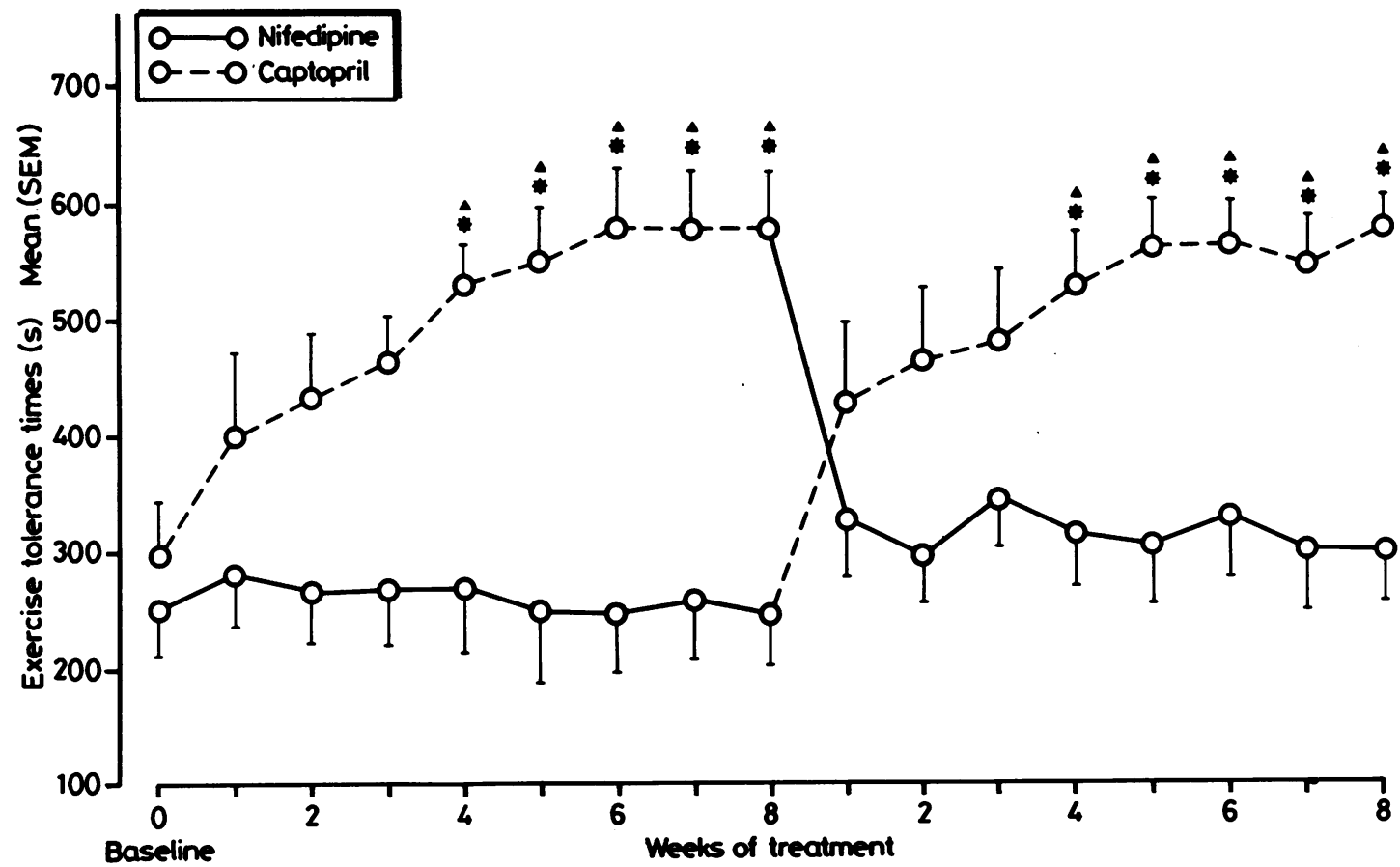

Fig. 2 Comparison of times of maximal physical capacity during nifedipine and captopril treatments. ${ }^{\star} V$ alue significantly different from baseline value $(p<0.01) ; \triangle$ Value significantly different from nifedipine treatment value $(p<0.01)$. 
Pble 2 (ilmical and humoral results with treatments in 18 patients with dilated cardiomyopathy

\begin{tabular}{|c|c|c|c|c|c|c|c|c|c|c|c|c|c|c|c|c|c|c|c|}
\hline \multicolumn{3}{|c|}{ IYHA class } & \multicolumn{3}{|c|}{ Body weight $\mathrm{kg}$} & \multirow{2}{*}{\multicolumn{3}{|c|}{$\begin{array}{l}\text { Serum potassium } \\
\text { mmol }\end{array}$}} & \multirow{2}{*}{\multicolumn{3}{|c|}{$\begin{array}{l}\text { Serum creatinine } \\
\text { Img dl }\end{array}$}} & \multicolumn{6}{|c|}{ Dependent oedema } & \multicolumn{2}{|c|}{ Symptoms that dereloped } \\
\hline \multirow{2}{*}{$B$} & \multirow{2}{*}{$N$} & \multirow{2}{*}{$C$} & \multirow{2}{*}{$B$} & \multirow{2}{*}{$N$} & \multirow{2}{*}{ C } & & & & & & & \multirow{2}{*}{$B$} & & \multirow{2}{*}{$N$} & \multirow{2}{*}{\multicolumn{3}{|c|}{$C$}} & \multirow{2}{*}{$N^{\prime}$} & \multirow{2}{*}{ C } \\
\hline & & & & & & $B$ & $N$ & C & $B$ & $\Lambda$ & C & & & & & & & & \\
\hline$t$ & 4 & 3 & $58 \cdot 5$ & 58 & $57 \cdot 2$ & $3 \cdot 8$ & $3 \cdot 5$ & $4 \cdot 1$ & $1 \cdot 8$ & $2 \cdot 0$ & $2 \cdot 2$ & + & + & $t$ & & + & & $\begin{array}{l}\text { Headache, } \\
\text { palpitation }\end{array}$ & - \\
\hline$t$ & 3 & 3 & 77 & $79 \cdot 2$ & $77 \cdot 6$ & $4 \cdot 2$ & $3 \cdot 9$ & $4 \cdot 5$ & $1 \cdot 1$ & $1 \cdot 2$ & $1 \cdot 2$ & + & & + & $t+$ & $+\quad+$ & & Palpitation & - \\
\hline$t$ & 4 & 3 & 81 & 82 & $80 \cdot 5$ & $4 \cdot 3$ & $3 \cdot 9$ & 48 & $1 \cdot 0$ & $1 \cdot 1$ & $1 \cdot 1$ & + & & + & $t+$ & $+\quad t$ & & Headache & \\
\hline 3 & 4 & 3 & $81 \cdot 6$ & 83 & $78 \cdot 2$ & $3 \cdot 7$ & $3 \cdot 3$ & $4 \cdot 2$ & $1 \cdot 9$ & $1 \cdot 4$ & $1 \cdot 6$ & () & & + & & () & & Palpitation & - \\
\hline 3 & 3 & 2 & $74 \cdot 4$ & $75 \cdot 4$ & $72 \cdot 2$ & $3 \cdot 5$ & $3 \cdot 3$ & $4 \cdot 0$ & $1 \cdot 7$ & $1 \cdot 5$ & $2 \cdot 2$ & 0 & & + & & 0 & & $\begin{array}{l}\text { Headache, } \\
\text { palpitation }\end{array}$ & - \\
\hline 4 & 3 & 3 & 88 & 89 & 87 & $3 \cdot 7$ & $3 \cdot 6$ & $4 \cdot 1$ & $1 \cdot 8$ & $1 \cdot 6$ & $1 \cdot 9$ & + & + & + & + & + & & - & - \\
\hline 3 & 4 & 3 & 63 & $62 \cdot 5$ & 62 & $4 \cdot 3$ & 3.9 & $4 \cdot 6$ & 1.5 & $1 \cdot 1$ & $1 \cdot 5$ & + & & + & & 0 & & Palpitation & 一 \\
\hline$t$ & 4 & 4 & 79 & 81 & 79 & $4 \cdot 5$ & $4 \cdot 3$ & $4 \cdot 4$ & 1.9 & $2 \cdot 0$ & $2 \cdot 8$ & + & + & + & $+t$ & $+t$ & & Palpitation & $\bar{r}$ \\
\hline$t$ & 4 & 3 & $77 \cdot 6$ & $79 \cdot 2$ & 77 & $4 \cdot 0$ & $3 \cdot 6$ & $4 \cdot 1$ & $1 \cdot 1$ & $1 \cdot 3$ & $1 \cdot 2$ & + & & + & $+t$ & $+\quad t$ & & - & I'aste alteration \\
\hline+ & 4 & 4 & $85 \cdot 8$ & $85 \cdot 6$ & $85 \cdot 7$ & $4 \cdot 1$ & $4 \cdot 1$ & $4 \cdot 5$ & $1 \cdot 2$ & $1 \cdot 3$ & $1 \cdot 1$ & + & $t+$ & + & $+t$ & $+\quad+$ & + & - & - \\
\hline+ & 3 & 3 & 86 & $87 \cdot 5$ & $84 \cdot 8$ & $3 \cdot 6$ & $3 \cdot 3$ & $4 \cdot 1$ & 1.9 & 1.7 & $1 \cdot 8$ & + & & + & + & + & + & Palpitation & - \\
\hline 3 & 3 & 3 & $80 \cdot 5$ & $81 \cdot 6$ & $77 \cdot 9$ & $4 \cdot 3$ & $4 \cdot 1$ & $4 \cdot 7$ & $1 \cdot 8$ & $1 \cdot 9$ & $2 \cdot 2$ & 0 & & + & & 0 & & Palpitation & - \\
\hline$t$ & 4 & 3 & 76 & $78 \cdot 8$ & $76 \cdot 5$ & $4 \cdot 4$ & $4 \cdot 1$ & $4 \cdot 7$ & $1 \cdot 6$ & $1 \cdot 8$ & $2 \cdot 2$ & + & & + & $+t$ & +0 & & Headache & Taste alteration \\
\hline 3 & 3 & 2 & 67 & 66 & 646 & $4 \cdot 0$ & $3 \cdot 6$ & $4 \cdot 7$ & $1 \cdot 8$ & $1 \cdot 8$ & $2 \cdot()$ & 0 & & 0 & & () & & - & - \\
\hline 4 & 4 & 4 & 88 & 89 & $87 \cdot 5$ & $3 \cdot 7$ & $3 \cdot 3$ & $4 \cdot 2$ & $1 \cdot 8$ & $1 \cdot 4$ & 17 & + & $t$ & + & $+t$ & $+\quad+$ & t & $\begin{array}{l}\text { Headache, } \\
\text { palpitation }\end{array}$ & - \\
\hline 3 & 4 & 3 & $61 \cdot 4$ & 65 & $60 \cdot 3$ & $4 \cdot 4$ & $4 \cdot 1$ & $4 \cdot 7$ & $1 \cdot 4$ & $1 \cdot 6$ & $1 \cdot 1$ & + & & + & & 0 & & - & - \\
\hline 3 & 3 & 2 & $65 \cdot 4$ & 65 & 64 & 3.6 & $3 \cdot 3$ & $4 \cdot 1$ & $1 \cdot 2$ & 1.5 & $1 \cdot 5$ & 0 & & 0 & & 0 & & Palpitation & - \\
\hline 4 & 4 & 3 & 73 & $76 \cdot 3$ & 72 & 3.9 & 3.9 & $4 \cdot 3$ & $1 \cdot 5$ & $1 \cdot 7$ & $1 \cdot 7$ & + & $t$ & + & $+t$ & $+\quad t$ & & Palpitation & - \\
\hline $3 n$ & 3.6 & $3 \cdot 1^{\star}$ & $75 \cdot 7$ & $76 \cdot 9^{\star}$ & $74 \cdot 7$ & $4 \cdot 0$ & $3 \cdot 7$ & $4 \cdot 4^{\star}$ & 16 & $1 \cdot 6$ & $1 \cdot 7$ & 一 & & - & & - & & - & - \\
\hline (1) 12 & 0.12 & $0 \cdot 14$ & $2 \cdot 2$ & $2 \cdot 3$ & $2 \cdot 3$ & 0.08 & 0.08 & 0.06 & 0.07 & 0.07 & 0.11 & & & & & & & & \\
\hline
\end{tabular}

imificantly different $(p<0.01)$ from basal values

besal; N. nifedipine; C, captopril; NYHA, New York Heart Association.

lar resistance and was associated with a $12^{\prime \prime} "$, rise in cardiac index. Mean pulmonary arterial pressure, pulmonary arteriolar resistance, and the pulmonary capillary wedge pressure tended to decrease, although these changes were not statistically significant. After long term treatment the response was substantially different. In fact, changes from baseline in mean arterial pressure, and cardiac index were less pronounced and were no longer statistically significant; heart rate and pulmonary capillary wedge pressure showed a clear tendency to increase.

The response to oral captopril was also greatest approximately $1.5 \mathrm{~h}$ after administration. In five patients the first dose induced considerable increases in cardiac index and stroke volume index and decreases in mean arterial pressure, heart rate, systemic vascular resistance, and pulmonary capillary wedge pressure, which were sustained after eight weeks of continuous treatment. Four patients had minimal haemodynamic responses to the first $50 \mathrm{mg}$ of the drug and also showed small changes when up to three times this dose was given. Despite the reduced initial response they continued on the standard protocol and were treated with the standard dosage. Repeat assessment after eight weeks of continuous treatment showed a spontaneous improvement of efficacy in three patients, in whom values became similar to those of the early responders in the same group. Because of this pattern, which has been reported by others, ${ }^{1516}$ overall haemodynamic changes from baseline that were present in the short term study were much more pronounced at long term re-evaluation (Fig. 3 ).

Figure 4 shows means for the circulatory variables that were recorded in the entire population at baseline and after long term treatment with both agents. The changes induced by captopril and nifedipine moved in the same direction, as shown in Fig. 3. This indicates that the sequence of drug administration did not interfere with the quality of the response to the treatments. Cardiothoracic ratios measured by independent observers on standard chest $x$ rays were significantly reduced after captopril. The mean control ratio was 0.575 compared with a mean ratio of 0.560 after two months of captopril treatment $(\mathrm{p}<0.01)$.

Left ventricular end systolic circumferential wall stress (mean for the entire population with the exception of six patients) was significantly reduced by captopril and to a lesser extent and not significantly by nifedipine at the end of the treatment period; the force-length relation was shifted to the left after captopril but not after nifedipine (Fig. 5).

No patients had to stop taking captopril or nifedipine during the study because of adverse reactions (Fig. 1).

While on nifedipine five patients complained of headache and 11 reported palpitation that was described as disturbing by six. We do not know whether this symptom was associated with wors- 

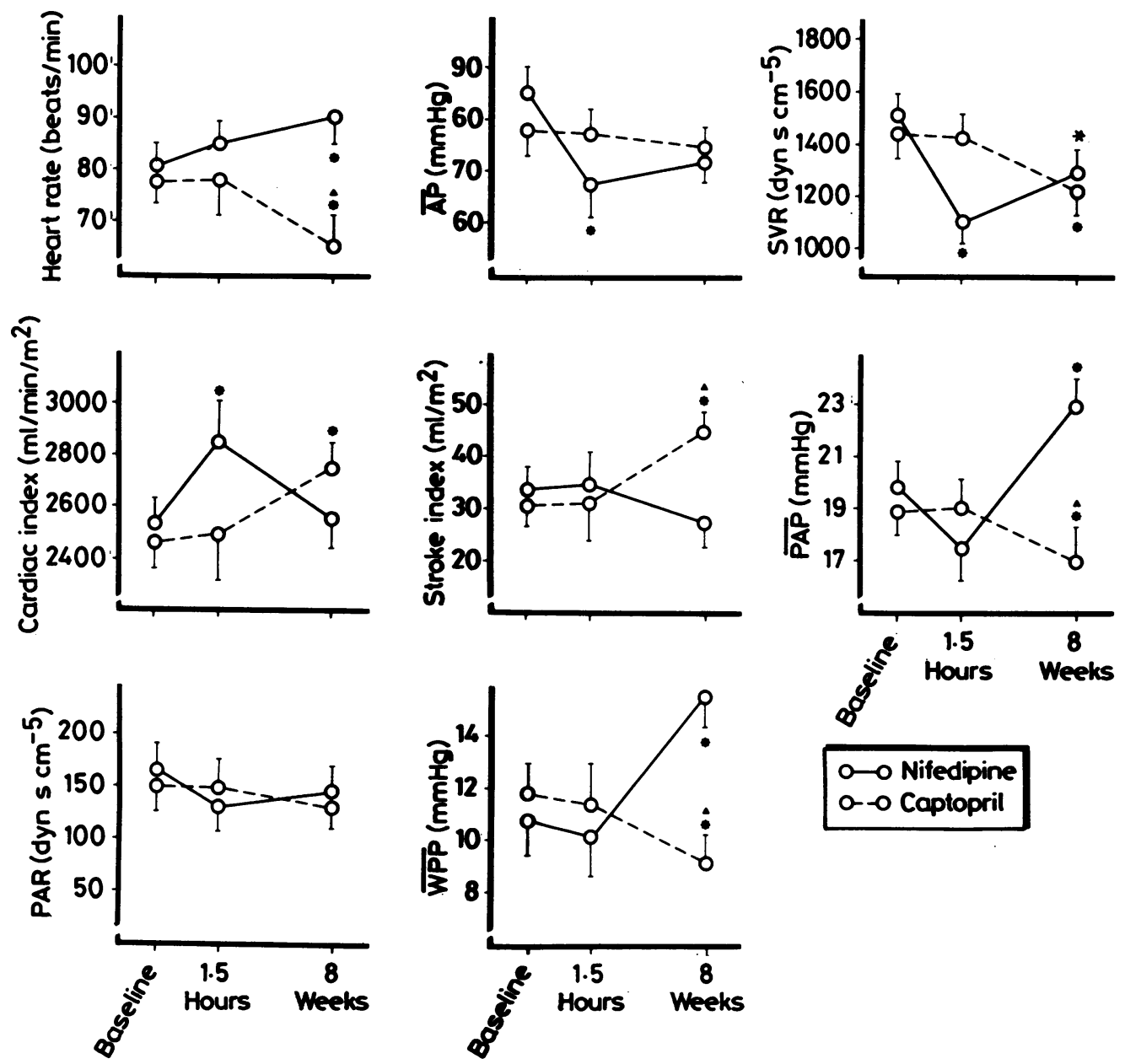

Fig. 3 Haemodynamic values (mean (SD)) at baseline, after 1.5 hours, and after eight weeks of treatment in patients given captopril (nine cases) and nifedipine (nine cases) as the first drug. $\overline{A P}$, mean arterial pressure; SVR, systemic vascular resistance; PAR, pulmonary arteriolar resistance; $W P P$, mean pulmonary capillary wedge pressure; $\overline{P A P}$, mean pulmonary arterial pressure. ${ }^{*}$ Value significantly different from baseline value $(p<0.01)$; $\Delta$ Value significantly different from nifedipine treatment value $(p<0.01)$.

ening arrhythmia because we did not evaluate this. We also found an increase in body weight in 12 patients and enhancement of dependent oedema in 11 while they were on nifedipine. This latter effect, however, may not necessarily be due to cardiac causes. ${ }^{17}$ Nifedipine also reduced mean serum potassium concentration and did not depress renal function (Table 2).

Captopril did not lead to the development of dependent oedema or increase body weight. Two patients on this treatment complained of a slight and transient taste alteration; in one patient serum creatinine concentration rose from 1.9 to $2.8 \mathrm{mg} / \mathrm{dl}$; mean serum potassium rose from a baseline concen- tration of $4.0 \mathrm{mmol} / 1$ to $4.4 \mathrm{mmol} / 1(\mathrm{p}<0.01)$; this was also significantly higher than the concentration $(3.7 \mathrm{mmol} / \mathrm{l})$ on nifedipine (Table 2$)$.

\section{Discussion}

In this study two potent vasodilators with different mechanisms of action were used to treat heart failure due to cardiomyopathy. Captopril or nifedipine were given with a fixed regimen of digitalis and diuretics in a double blind crossover trial. Captopril significantly improved the New York Heart Association functional class and exercise tolerance times. The incorporation of captopril into conventional 

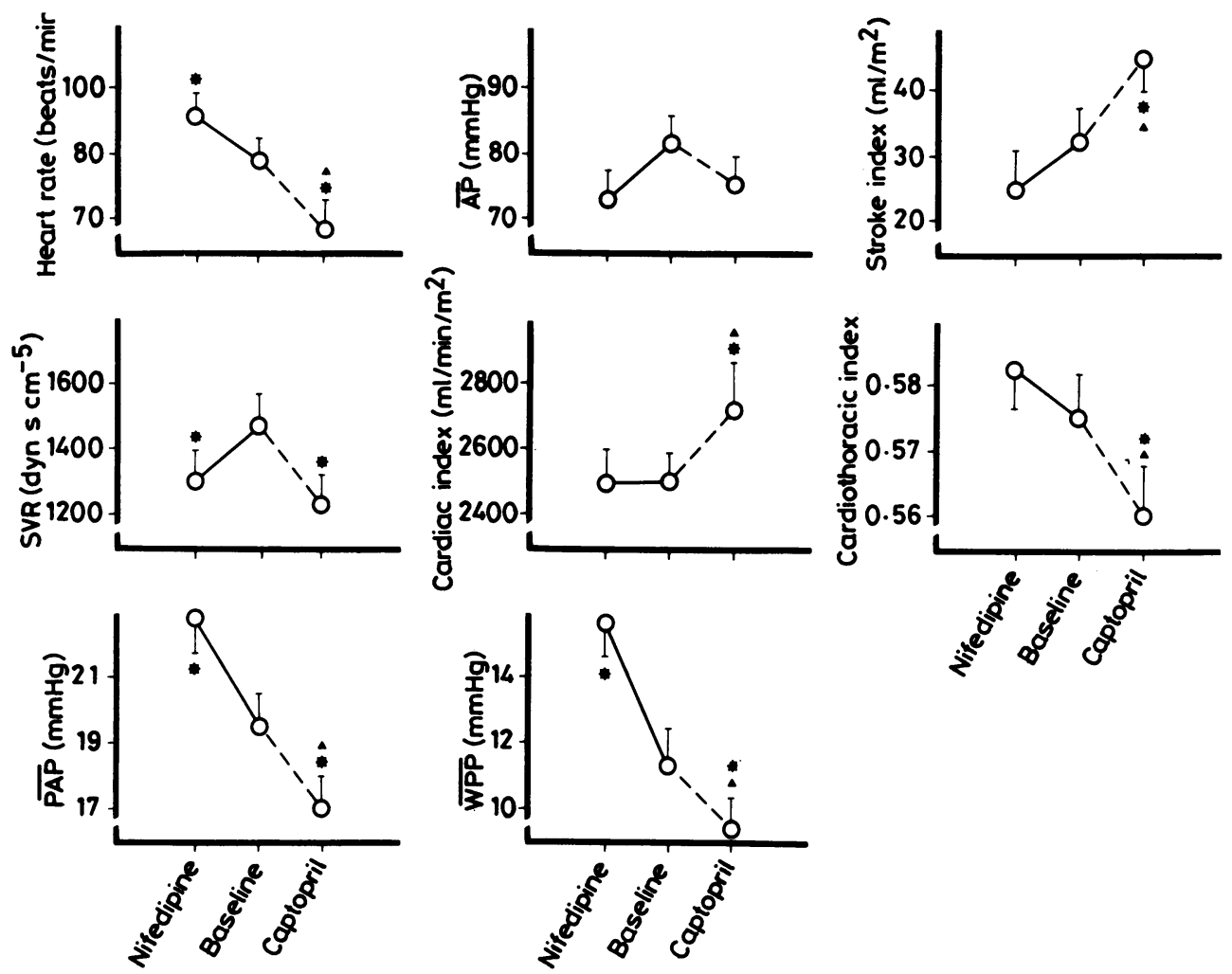

Fig. 4 Haemodynamic values (mean (SD)) of the entire population at baseline and after eight weeks' treatment with captopril and nifedipine. $\overline{A P}$, mean arterial pressure; SVR, systemic vascular resistance; $\overline{P A P}$, mean pulmonary arterial pressure; WPP, mean pulmonary capillary wedge pressure. ${ }^{V}$ alue significantly different from baseline value $(p<0.01) ; \Delta$ Value significantly different from nifedipine treatment value $(p<0.01)$.

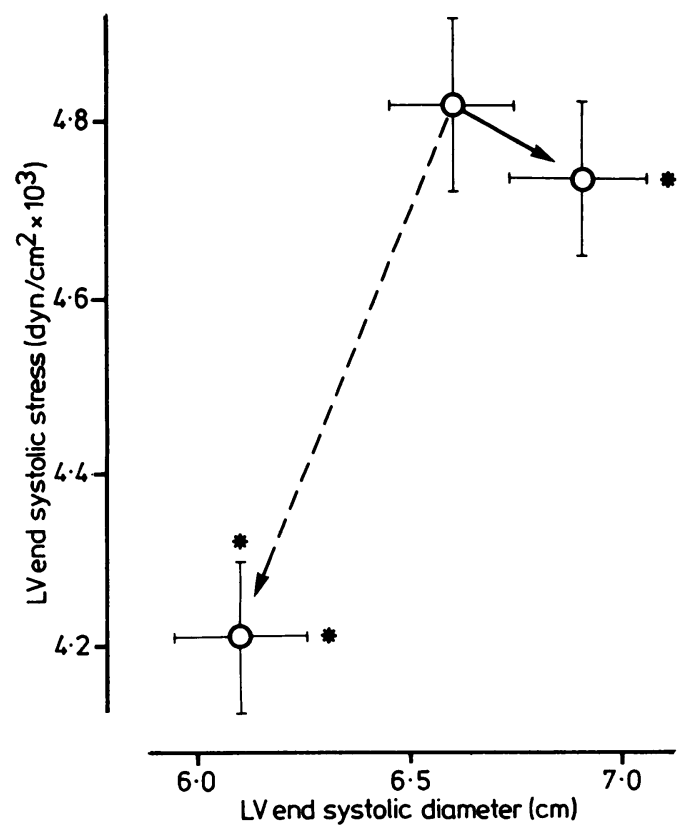

Fig. 5 Relation between left ventricular end systolic wall stress and left ventricular end systolic internal diameter at baseline and after eight weeks' treatment with captopril (broken arrow) and after eight weeks' treatment with nifedipine (solid arrow). Circles represent the means and lines the $S D .{ }^{\star} p<0.01$ for differences in wall stress and diameter between baseline and treatment. 
heart failure treatment permitted patients who were incapacitated by symptoms to perform at least a moderate physical exertion. A training effect is unlikely to be responsible for this result because the physical tests were of short duration and infrequent. Nifedipine did not relieve symptoms, and made some patients worse. In the long term trial the significant reduction of the pulmonary capillary wedge pressure and the increase of cardiac output by captopril but not by nifedipine showed that at least part of the increased functional capacity might be the result of an improved performance of the left ventricle.

Did vasodilating potency or some other factor influence responses to the two drugs? In the short term study systemic vascular resistance was consistently reduced by nifedipine, cardiac output was raised, and the left ventricular filling pressure tended to fall. This pattern was similar to the response to nifedipine reported in patients with dilated cardiomyopathy and acute pulmonary oedema. ${ }^{5-7}$ During prolonged treatment, however, cardiac output did not improve and the pulmonary capillary wedge pressure rose substantially, indicating that the benefits of the reduced impedence to left ventricular ejection observed in the short term study were lost, even though the vasodilating action of nifedipine persisted. Changes in systemic vascular resistance after prolonged administration of captopril resembled those produced by nifedipine, but captopril improved the performance of the left ventricle, as indicated by the filling pressure-cardiac output relation.

Heart rate was increased (by an average of nine beats $/ \mathrm{min}$ ) on nifedipine and reduced (by an average of 11 beats $/ \mathrm{min}$ ) on captopril. This finding may be relevant to the different haemodynamic effects of the two agents since the greater the dysfunction of a ventricle the higher its sensitivity to changes in afterload. ${ }^{18}$ Also when the cavity becomes enlarged and systolic wall thickening is diminished, as in dilated cardiomyopathy, ventricular dimension becomes an important determinant of afterload. In such a situation, if cardiac output remains constant, afterload may vary in parallel with heart rate, because the ventricular cavity is reduced more during systole when heart rate is slow than when it is fast. Indeed captopril treatment was associated with an increased stroke index.

End systolic stress represents the critical afterload value which terminates ventricular ejection ${ }^{19}$ and measurement of end systolic stress is a good index of the role of afterload in determining ventricular pump function. We assessed end systolic left ventricular circumferential wall stress by a non-invasive method, although we were aware that echo- cardiographic measurements in patients with dilated hearts are liable to error and that the reproducibility may be unsatisfactory. In order to improve the reliability and reproducibility of such measurements we used appropriate techniques and criteria of recording, coded the echocardiograms, read them blindly and in random order, and took the average of triplicate measurements for each period. The correspondence in most cases between changes in ventricular cavity dimensions evaluated by ultrasound and changes in cardiothoracic ratio, and the uniformity of the trends during treatment indicate that our echocardiographic records were reliable.

The minor axis of the left ventricle at end systole was significantly reduced by captopril but not by nifedipine, and end systolic afterload was reduced by captopril and not by nifedipine (Fig. 5), even though the reduction of systemic vascular resistance and possibly of aortic impedence was similar with the two treatments.

The leftward shift of the force-length relation after captopril may indicate either a shift to a different point in the same basal stress-length line (which would indicate no change in contractility) or a displacement to the left of the force-length line itself (which would indicate improved contractility). ${ }^{1314}$ This relation tended to move rightward when patients were treated with nifedipine, indicating that some depression in contractility may have occurred.

The reduction in heart rate with captopril, which has been reported in several previous studies, ${ }^{91620}$ may be due to the absence of a facilitating action of angiotensin II on the sympathetic neurotransmission, ${ }^{21}$ or to reduction of catecholamine release, ${ }^{17}$ or to venodilatation. Captopril causes both venodilatation and arteriolar dilatation and hence heart rate may remain constant. ${ }^{17}$ If the adrenergic drive to the heart were really depressed by captopril when there was a concomitant improvement in cardiac function, the hypothesis advanced by some ${ }^{22}$ that catecholamines are deleterious in primary cardiomyopathies would be reinforced.

In conclusion, the therapeutic efficacy and low frequency of important adverse effects indicate that captopril is useful in patients with decompensated dilated cardiomyopathies that are refractory to conventional treatment. The poor or adverse responses to nifedipine that we have reported in this study discourage its use in such patients.

\section{References}

1 Vidt DG, Bravo EL, Fouad F. Captopril. N Engl $\mathcal{Y}$ Med 1982; 306: 214-9. 
2 Dargie HJ, Ball SG, Atkinson AB, Robertson JIS. Converting enzyme inhibitors in hypertension and heart failure. Br Heart $\mathcal{F}$ 1983; 49: 305-8.

3 Abrams WB, Davies RO, Ferguson RK. Overview: the role of angiotensin converting enzyme inhibitors in cardiovascular therapy. Fed Proc 1984; 43: 1314-21.

4 Guazzi MD. Use of the calcium channel blocking agents in the treatment of systemic arterial hypertension. In: Stone PH, Antman EM, eds. Calcium channel blocking agents in the treatment of cardiovascular disorders. New York: Futura, 1983; 377-401.

5 Polese A, Fiorentini C, Olivari MT, Guazzi MD. Clinical use of a calcium antagonistic agent (nifedipine) in acute pulmonary edema. $A m \mathcal{F}$ Med 1979; 66: 825-30.

6 Matsumoto S, Ito T, Sada T, et al. Hemodynamic effects of nifedipine in congestive heart failure. $A m \mathcal{F}$ Cardiol 1980; 46: 476-80.

7 Ludbrook PA, Tiefenbrunn AJ, Reed FR, Sobel BE. Acute hemodynamic responses to sublingual nifedipine; dependence of left ventricular function. Circulation 1982; 65: 489-98.

8 Guazzi MD, Cipolla C, Della Bella P, Fabbiocchi F, Montorsi P, Sganzerla P. Disparate unloading efficacy of the calcium channel blockers, verapamil and nifedipine, on the failing hypertensive left ventricle. $A m$ Heart $\mathcal{f}$ 1984; 108: 116-23.

9 Davis R, Ribner HS, Keung E, Sonnenblick EH, Le Jemtel TH. Treatment of chronic congestive heart failure with captopril, an oral inhibitor of angiotensinconverting enzyme. $N$ Engl $f$ Med 1979; 301: 117-21.

10 Ader R, Chatterjee K, Ports T, Brundage B, Hiramatsu $B$, Parmley W. Immediate and sustained hemodynamic and clinical improvement in chronic heart failure by an oral angiotensin-converting enzyme inhibitor. Circulation 1980; 61: 931-7.

11 Captopril Multicenter Research Group. A placebocontrolled trial of captopril in refractory chronic congestive heart failure. $\mathcal{f}$ Am Coll Cardiol 1983; 2: 755-63.

12 Massie BM, Kramer BL, Topic N. Long-term cap- topril therapy for chronic congestive heart failure. $\mathrm{Am}$ f Cardiol 1984; 53: 1316-20.

13 Grossman W, Jones DM, Laurin LP. Wall stress and pattern of hypertrophy in the human left ventricle. $\mathcal{F}$ Clin Invest 1975; 56: 56-64.

14 Reichek N, Wilson J, Sutton MSJ, Plappert TA, Goldberg $S$, Hirshfeld JW. Noninvasive determination of left ventricular end-systolic stress: validation of the method and initial application. Circulation 1982; 65: 99-108.

15 Levine TB, Franciosa JA, Cohn JN. Acute and longterm response to an oral converting enzyme inhibitor, captopril, in congestive heart failure. Circulation 1980; 69: 35-41.

16 Packer M, Medina N, Yushak M, Meller J. Hemodynamic patterns of response during long-term captopril therapy for severe chronic heart failure. Circulation 1983; 68: 803-12.

17 Fouad FM, El-Tobgi S, Tarazi RC, et al. Captopril in congestive heart failure resistant to other vasodilators. Eur Heart f 1984; 5: 47-54.

18 Cohn JN, Franciosa JA. Vasodilator therapy of cardiac failure. $N$ Engl f Med 1977; 297: 27-31.

19 Weber KT, Janiki JJ. Instantaneous force-velocitylength relations: experimental findings and clinical correlates. Am ₹ Cardiol 1977; 40: 740-7.

20 Guazzi MD, De Cesare N, Galli C, et al. Calciumchannel blockade with nifedipine and angiotensin converting-enzyme inhibition with captopril in the therapy of patients with severe primary hypertension. Circulation 1984; 70: 279-84.

21 Antonaccio MJ, Kerwin L. Pre- and postjunctional inhibition of vascular sympathetic function by captopril in SHR. Implication of vascular angiotensin II in hypertension and antihypertensive actions of captopril. Hypertension 1981; 3: I-54-62.

22 Swedberg K, Hjalmarson A, Waagstein F, Wallentin I. Beneficial effects of long-term beta-blockade in congestive cardiomyopathy. Br Heart $\mathcal{F}$ 1980; 44: 117-33. 